\title{
Clinical outcomes of surgical management for primary gastrointestinal diffuse large B-cell lymphoma: At a single institution experience
}

\author{
Sung Woo Jang, Dae Ro Lim, Jung Kul Kuk, Taehyung Kim, Eung Jin Shin \\ Division of Colon and Rectal Surgery, Department of Surgery, Soonchunhyang University Bucheon Hospital, Soonchunhyang University College of \\ Medicine, Bucheon, Korea
}

Purpose: The study aimed to analyze peri/postoperative outcomes and long-term oncologic outcomes after surgical management for primary gastrointestinal diffuse large B-cell lymphoma (DLBL).

Methods: Between January 2001 and December 2013, 19 patients who underwent surgery for primary gastrointestinal DLBL were retrieved from a retrospective database.

Results: With a median follow up of 49.2 months, the most common tumor locations were the terminal ileum and cecum $(n=14,73.7 \%)$ and stomach $(n=4,21.1 \%)$. The most common clinical symptoms were abdominal pain $(n=15,78.9 \%)$ and intussusceptions $(n=5,26.3 \%)$. None of the patients had B symptoms. Emergency surgery was undertaken in $36.8 \%(n=7)$ of the patients. Mean mass size was $8.4 \mathrm{~cm} ; 4$ patients $(21.1 \%)$ had a bulky mass $(>10 \mathrm{~cm})$. The International Prognostic Index (IPI) scores were low $(n=11,57.9 \%)$, low-intermittent $(n=7$, $36.8 \%)$, and high-intermittent $(n=1,5.3 \%)$. Patients' staging was IE $(n=9,47.4 \%)$, IIE $(n=8,42.1 \%)$, and IVE $(n=2,10.5 \%)$ based on the Ann Arbor staging system, and I $(n=2,10.5 \%)$, III $(n=5,26.4 \%)$, IIE $(n=10,52.6 \%)$, and IV $(n=2,10.5 \%)$ based on the Lugano staging system. B-lymphocyte antigen CD20 was positive in most patients $(n=17,89.5 \%)$ and Ki-67 was high $(>70 \%)$ in 12 patients $(63.2 \%)$. Two types of chemotherapy were administered: cyclophosphamide, hydroxydaunorubicin, oncovin, and prednisolone $(n=5,26.3 \%)$, rituximab, cyclophosphamide, hydroxydaunorubicin, oncovin, and prednisolone $(n=13,68.4 \%)$. The 5 -year disease-free survival rate was $94.4 \%$ and the 5-year overall survival rate was $89.5 \%$.

Conclusion: Surgery for primary gastrointestinal DLBL is feasible and acceptable. Low staging of primary gastrointestinal DLBL has good prognosis.

Keywords: Lymphoma, Diffuse large B-cell lymphoma, Gastrointestinal tract, Surgery

\section{INTRODUCTION}

Primary gastrointestinal lymphoma is a very rare disease; it only accounts for $1 \%-4 \%$ of all gastrointestinal cancers [1]. Malignant lymphoid neoplasms are classified into Hodgkin's disease and non-Hodgkin's malignant lymphoma. Non-Hodgkin's malignant

Received: Sep 18, 2017 Accepted: Nov 01, 2017

Correspondence to: Eung Jin Shin

Section of Colon and Rectal Surgery, Department of Surgery,

Soonchunghyang University Bucheon Hospital, Soonchunhyang University College of Medicine, 170 Jomaru-ro, Wonmi-gu, Bucheon 14584, Korea

Tel: +82-32-621-6267, Fax: +82-32-621-6950

E-mail: colon@schmc.ac.kr

Copyright @ C Korean Society of Surgical Oncology

This is an Open Access article distributed under the terms of the Creative Commons Attribution Non-Commercial License (http://creativecommons.org/licenses/by-nc/4.0) which permits unrestricted non-commercial use, distribution, and reproduction in any medium, provided the original work is properly cited. lymphomas are classified as nodal and extranodal lymphomas [2]. The gastrointestinal tract is the most common site of extranodal malignant lymphoma, accounting for $5 \%-20 \%$ of all cases [3]. The gastrointestinal tract is also the most common site of extranodal lymphoma for diffuse large B-cell lymphoma (DLBL) [2]. Primary gastrointestinal lymphoma has been classified histologically as B-cell lymphoma and T-cell lymphoma. The B-cell lymphoma group is divided into the following subtypes: mucosa associated lymphoid tissue, DLBL, follicular lymphoma, mantle cell lymphoma, and Burkitt lymphoma. The T-cell lymphoma group is divided into the following subtypes: enteropathy associated T-cell lymphoma, natural killer (NK)/T-cell lymphoma, and peripheral T-cell lymphoma [4]. Almost $90 \%$ of all gastrointestinal lymphomas are B-cell lymphomas, and the main histological subtype is DLBL, which constitutes $45 \%-59 \%$ of all gastrointestinal lymphoma $[5,6]$. Treatment of primary gastrointestinal DLBL is still a controversial 
issue. Because primary gastrointestinal DLBL is a very rare disease, and there are few large scale prospective randomized studies, there is no consensus on the optimal treatment. The present study aimed to analyze peri/postoperative outcomes and long-term oncologic outcomes after surgical management for primary gastrointestinal DLBL at the single institution.

\section{METHODS}

Ethical approval was not necessary as this study was based on retrospective review.

Between January 2001 and December 2013, all patients $(\mathrm{n}=19)$ that underwent surgical management for primary DLBL were identified from a retrospective database. All data of the clinical and pathological features were reviewed retrospectively. Gastrointestinal intestinal DLBL satisfied the lymphoma definition of Lewin et

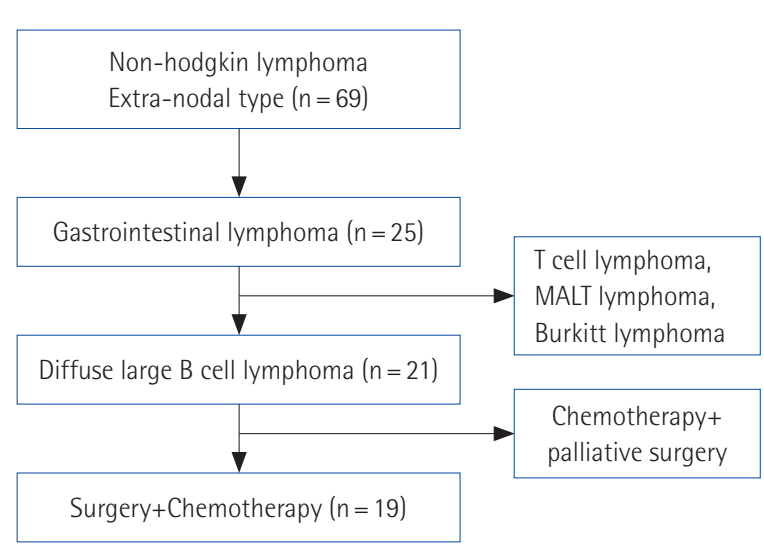

Fig. 1. Patients included in this study. MALT, mucosa-associated lymphoid tissue. al. [7]. A total of 19 patients were included in this study, of which 69 were extranodal type of Non-Hodgkin lymphoma patients, 25 were gastrointestinal lymphoma and 21 were primary gastrointestinal DLBCL patients. Of these patients, a total of 19 patients were included in the study, excluding 2 patients who underwent palliative surgery during chemotherapy (Fig. 1). All patients underwent surgery and adjuvant chemotherapy using cyclophosphamide, hydroxydaunorubicin, oncovin, and prednisolone (CHOP) or rituximab CHOP (R-CHOP) regimens except postoperative mortality. All patients underwent gastroduodenoscopy, colonoscopy, and a biopsy, staging scans (computed tomography scan of the chest, abdomen, and pelvis) and, occasionally, positron emission tomography-computed tomography scans. B symptoms were defined as fever $\left(>38^{\circ} \mathrm{C}\right)$, weight loss without trying, exceeding $10 \%$ of body weight in 6 months, and drenching night sweats. The Eastern Cooperative Oncology Group (ECOG) performance status grade was used, as defined by Oken et al. [8]. Bulky mass was defined as a mass with a diameter greater than $10 \mathrm{~cm}$. The International Prognostic Index (IPI) score was calculated using the following parameters: age $\geq 60$ years, ECOG status $\geq 2$, elevated lactate dehydrogenase, Ann Arbor stage III or IV, $\geq 2$ extranodal disease sites [9]. The IPI score was defined as follows: low (0 or 1), low-intermediate (2), high-intermediate (3), or high (4 or 5) [10]. The depth of the tumor invasion and the extent of nodal involvement were described as a parameter for stage classification in three staging systems: the Paris staging system, the Ann Arbor staging system, and the Lugano staging system (Table 1). The Paris staging system was based on the 6th edition of the American Joint Committee on Cancer's tumor-node-metastasis (TNM) [9]. In the Paris staging system the distribution of stage is: T1, tumor confined to the mucosa and/or submucosa; T2, tumor infiltrates the muscularis pro-

Table 1. Staging of gastrointestinal diffuse large B cell lymphoma

\begin{tabular}{|c|c|c|c|c|}
\hline Stage & Lugano stage & Paris TNMB stage & Modified Ann Arbor stage & Tumor involvement \\
\hline \multirow[t]{3}{*}{ I } & Confined to Gl tract (single primary or multiple, & T1NOMOBO & $\mathrm{IE}$ & Mucosa, submucosa \\
\hline & & T2NOMOBO & $\mathrm{IE}$ & Muscularis propria \\
\hline & & T3NOMOBO & $\mathrm{IE}$ & Serosa \\
\hline \multirow[t]{2}{*}{$\|$} & $\begin{array}{l}\text { Extending into abdomen } \\
\| 11=\text { local nodal involvement }\end{array}$ & T1-3N1MOB0 & IIE & Perigastric or peri-intestinal lymph nodes \\
\hline & II2 = distant nodal involvement & T1-3N2MOBO & $\| \mathrm{E}$ & More distant regional lymph nodes \\
\hline IIE & $\begin{array}{l}\text { Penetration of serosa to involve adjacent organs or } \\
\text { tissues }\end{array}$ & T4NOMOBO & IE & Invasion of adjacent structures \\
\hline \multirow[t]{3}{*}{ IV } & $\begin{array}{l}\text { Disseminated extranodal involvement or concomitant } \\
\text { supradiaphragmatic nodal involvement }\end{array}$ & T1-4N3MOBO & IIIE & $\begin{array}{l}\text { Lymph nodes on both sides of the dia- } \\
\text { phragm }\end{array}$ \\
\hline & & T1-4N0-3M1B0 & IVE & $\begin{array}{l}\text { Distant metastases (e.g., bone marrow or } \\
\text { additional extranodal sites) }\end{array}$ \\
\hline & & T1-4No-3MO-1B0 & IVE & \\
\hline
\end{tabular}


pria and/or submucosa; $\mathrm{T} 3$, tumor penetrates the serosa (visceral peritoneum) without invasion of adjacent structures; T4, tumor perforates the serosa or invades the adjacent structures organs; $\mathrm{N} 1$, involvement of regional lymph nodes; $\mathrm{N} 2$, involvement of intra-abdominal lymph nodes beyond the regional area; N3, the tumor spreads to the extra-abdominal lymph nodes; M1, non-continuous involvement of a separate site in the gastrointestinal tract (e.g., stomach and rectum); M2, non-continuous involvement of other tissues (e.g., peritoneum pleura) or organs (e.g., tonsils, parotid gland, ocular adnexa, lung, liver, spleen, kidney, breast, etc.); $\mathrm{BX}$, involvement of bone marrow not assessed; B0, no evidence of bone marrow involvement; and B1, lymhomatous infiltration of bone marrow [10,11]. In the Ann Arbor staging system, the distribution of stage is: I, if a single lymph node region is involved; IE, if a single extralymphatic organ or site is involved; II, if two or more lymph node regions on the same side of the diaphragm are involved; IIE, if involvement is localized to an extralymphatic organ or site and one or more lymph node regions on the same side of the diaphragm; III, if lymph node regions on both sides of the diaphragm are involved; IIIE, if the extralymphatic site is involved; and IV, diffuse or disseminated involvement of one or more extralymphatic organs or tissues; with or without associated lymph node involvement [12]. In the Lugano staging system, the distribution of stage is: I, confined to GI tract (single primary or multiple, noncontiguous); II1, extending into the abdomen with local nodal involvement; II2, extending into the abdomen with distant nodal involvement; IIE, penetration of the serosa to involve adjacent organs or tissues; and IV, disseminated extranodal involvement or concomitant supradiaphragmatic nodal involvement [13]. In the present study, the patients received close follow-up and the findings were recorded in a database until death or August 2017. The patients received follow-up every 3-6 months for up to 5 years after surgery. Disease-free survival (DFS) was defined from the date of surgery to the date of the detection of recurrence or the last follow-up, or death.

\section{Statistical analysis}

All statistical analyses were performed using SAS ver. 9.1.3 (SAS Institute Inc., Cary, NC, USA) and IBM SPSS software, ver. 24.0 (IBM Corp., Armonk, NY, USA). The categorical variables were analyzed using the $\chi^{2}$ or Fisher's exact test, and the continuous variables were analyzed using the Student t-test/Mann-Whitney U rank tests. Cumulative-incidence methods were used to estimate the rate of cancer recurrence. Overall survival (OS) and DFS were analyzed using the Kaplan-Meier method.

\section{RESULTS}

\section{Patient characteristics}

The mean age of the patients was $52.5 \pm 15.8$ years. Of the 19 patients, 14 (73.7\%) were male and $5(26.3 \%)$ were female. Mean weight was $63.7 \pm 12.6 \mathrm{~kg}$ and mean height was $165.0 \pm 8.3 \mathrm{~cm}$. Mean body mass index (BMI) was $23.1 \pm 3.2 \mathrm{~kg} / \mathrm{m}^{2}$. The American society of anesthesiologists scores were $1(\mathrm{n}=11,57.9 \%), 2(\mathrm{n}=3$, $42.1 \%)$, and $3(n=0,0.0 \%)$. The ECOG performance status results were $0(\mathrm{n}=14,73.7 \%), 1(\mathrm{n}=4,21.1 \%)$, and $2(\mathrm{n}=1,5.3 \%)$. The tumor was located in the stomach in 4 patients (21.1\%), the terminal ileum in $4(21.1 \%)$ patients, the terminal ileum and cecum in 7 (36.8\%) patients, the cecum in $3(15.8 \%)$ patients, and the appendix in $1(5.3 \%)$ patient. Adjuvant chemotherapy was administered using CHOP $(n=5,26.3 \%)$ and R-CHOP $(n=13,68.4 \%)$ (Table 2$)$.

\section{Clinical symptoms}

The primary clinical symptom was abdominal pain $(\mathrm{n}=15$,

Table 2. Patients characteristics $(n=19)$

\begin{tabular}{lc}
\hline Characteristic & Patients $(\mathrm{n}=19)$ \\
\hline Age $(\mathrm{yr})$ & $52.5 \pm 15.8(15-82)$ \\
Sex & $14(73.7)$ \\
Male & $5(26.3)$ \\
Female & $63.7 \pm 12.6(40.0-83.0)$ \\
Weight $(\mathrm{kg})$ & $165.0 \pm 8.3(150.0-179.3)$ \\
Height $(\mathrm{cm})$ & $23.1 \pm 3.2(15.8-27.5)$ \\
BMI (kg/m $\left.{ }^{2}\right)$ & \\
ASA score & $11(57.9)$ \\
1 & $8(42.1)$ \\
2 & 0 \\
3 & \\
ECOG performance status & $14(73.7)$ \\
0 & $4(21.1)$ \\
1 & $1(5.3)$ \\
2 & \\
Tumor location & $4(21.1)$ \\
Stomach & $4(21.1)$ \\
Terminal ileum & $7(36.8)$ \\
Terminal ileum \& cecum & $3(15.8)$ \\
Cecum & $1(5.3)$ \\
Appendix & \\
Adjuvant chemotherapy & $5(26.3)$ \\
CHOP & $13(68.4)$ \\
R-CHOP &
\end{tabular}

Values are presented as mean \pm standard deviation (range) or number (\%). BMI, body mass index; ASA, American society of anesthesiologists; ECOG, Eastern Cooperative Oncology Group; CHOP, cyclophosphamide, hydroxydaunorubicin, oncovin, and prednisone; R-CHOP, rituximab, cyclophosphamide, hydroxydaunorubicin, oncovin, and prednisolone. 
78.9\%). The second most common symptom was intussusception $(\mathrm{n}=5,26.3 \%)$. Other symptoms were nausea $(\mathrm{n}=3,15.8 \%)$, palpable mass $(n=3,15.8 \%)$, vomiting $(n=2,10.5 \%)$, hematochezia $(\mathrm{n}=2,10.5 \%)$, and bowel perforation $(\mathrm{n}=2,10.5 \%)$. None of the patients had any B symptoms. Three of the 19 patients had no any symptoms (15.8\%). None of the patients had anemia. Mean hemoglobin level was $12.9 \pm 1.5 \mathrm{~g} / \mathrm{dL}$ (range, $15.4-10.6 \mathrm{~g} / \mathrm{dL}$ ). Mean albumin level was $4.0 \pm 0.4 \mathrm{~g} / \mathrm{dL}$ (range, $4.6-3.1 \mathrm{~g} / \mathrm{dL}$ ). Mean lactate dehydrogenase level was 419.8 $\pm 148.1 \mathrm{IU} / \mathrm{L}$ (717.0-244.0 IU/L). The number of elevated lactate dehydrogenase patients was 5 (26.3\%). Mean carcinoembryonic antigen level was $1.1 \pm 0.6 \mathrm{ng} /$ $\mathrm{mL}(1.82-0.07 \mathrm{ng} / \mathrm{mL})$ (Table 3).

\section{Surgery for gastrointestinal DLBL}

The indications for surgery were symptomatic and had a mass in gastrointestinal tract, which was to improve the symptoms. In addition, if the tumor is found without any symptoms and the malignancy is suspected, surgery is performed. A total of 14 patients (73.7\%) were suspected of having malignancy, and 3 patients (21.4\%) had no symptoms among these patients. Subtotal gastrectomy with lymph node dissection for rule out malignancy was performed in 4 patients (21.1\%). Right hemicolectomy with lymph node dissection for rule out malignancy was performed in $10 \mathrm{pa}-$ tients (52.6\%). Ileocecetomy was performed in 2 patients (10.5\%). Segmental resection small bowel was performed in 2 patients (10.5\%). Appendectomy was performed in 1 patient (5.3\%). Emergency surgery was performed in 7 patients (36.8\%). Laparoscopic

Table 3. Clinical symptoms of gastrointestinal diffuse large B cell lymphoma

\begin{tabular}{lc}
\hline Clinical symptoms & Patients $(\mathrm{n}=19)$ \\
\hline Abdominal pain & $15(78.9)$ \\
Nausea & $3(15.8)$ \\
Vomiting & $2(10.5)$ \\
Hematochezia & $2(10.5)$ \\
Palpable mass & $3(15.8)$ \\
B symptom & 0 \\
No symptom & $3(15.8)$ \\
Intussusception & $5(26.3)$ \\
Perforation & $2(10.5)$ \\
Hemogrobin (g/dL) & $12.9 \pm 1.5(15.4-10.6)$ \\
Albumin (g/dL) & $4.0 \pm 0.4(4.6-3.1)$ \\
LDH (IU/L) & $419.8 \pm 148.1(717.0-244.0)$ \\
Elevated LDH, no (\%) & $5(26.3)$ \\
CEA (ng/mL) & $1.1 \pm 0.6(1.82-0.07)$ \\
\hline
\end{tabular}

Values are presented as number (\%) or mean \pm standard deviation. $\mathrm{LDH}$, lactate dehydrogenase level; CEA, carcinoembryonic antigen. surgery was performed in 2 patients (10.5\%). Open surgery was performed in 17 patients (89.5\%). A total of 5 patients $(26.3 \%)$ had postoperative complications. Two patients (10.5\%) had ileus. Three patients (15.8\%) had a wound infection. One patient (5.3\%) had disseminated intravascular coagulation. Postoperative mortality occurred in 1 patient (5.3\%). The reason of mortality was massive postoperative bleeding and disseminated intravascular coagulation. The patient was 70 years old female and was performed subtotal gastrectomy.

Mean mass size was $8.4 \pm 5.3 \mathrm{~cm}$ (range, $3.0-26.0 \mathrm{~cm}$ ). Four patients $(21.1 \%)$ had a bulky mass ( $>10 \mathrm{~cm}$ ). Mean harvested lymph node was $23.2 \pm 21.1$ (range, $0-62.0$ ). The number of positive lymph nodes was $2.2 \pm 3.8$ (range, $0.0-11.0$ ) (Table 4 ).

\section{Pathologic findings after gastrointestinal DLBL surgery}

All patients were diagnosed with DLBL through pathologic results after surgery. Distribution of stage was classified using the Paris classification system, the Ann Arbor staging system, and the Lugano staging system. The Paris classification results were: $\mathrm{T} 1(\mathrm{n}=0$, $0.0 \%)$, T2 $(\mathrm{n}=3,15.8 \%), \mathrm{T} 3(\mathrm{n}=14,73.7 \%)$, T4 $(\mathrm{n}=2,10.5 \%)$, N0 $(\mathrm{n}=10,52.6 \%), \mathrm{N} 1(\mathrm{n}=4,21.1 \%), \mathrm{N} 2(\mathrm{n}=5,26.3 \%), \mathrm{N} 3(\mathrm{n}=0$, $0.0 \%)$, M0 ( $n=19,0.0 \%)$, M1 ( $\mathrm{n}=0,0.0 \%)$, M2 ( $\mathrm{n}=0,0.0 \%), \mathrm{Bx}$ $(\mathrm{n}=17,89.5 \%), \mathrm{B} 0(\mathrm{n}=2,10.5 \%)$, and B1 $(\mathrm{n}=0,0.0 \%)$. The Ann Arbor staging results were: IE ( $n=9,47.4 \%)$, IIE ( $n=8,42.1 \%)$, IIIE

Table 4. Surgery for gastrointestinal diffuse large B cell lymphoma

\begin{tabular}{lc}
\hline Surgery & Patients $(n=19)$ \\
\hline Subtotal gastrectomy & $4(21.1)$ \\
Right hemicolectomy & $10(52.6)$ \\
Ileocecectomy & $2(10.5)$ \\
Segmental resection & $2(10.5)$ \\
Appendectomy & $1(5.3)$ \\
Emergency surgery & \\
Yes & $7(36.8)$ \\
No & $12(63.2)$ \\
Laparoscopic surgery & $2(10.5)$ \\
Open surgery & $17(89.5)$ \\
Total number of postoperative complication & $5(26.3)$ \\
lleus & $2(10.5)$ \\
Wound infection & $3(15.8)$ \\
Bleeding & 0 \\
Disseminated intravascular coagulation & $1(5.3)$ \\
Mortality & $1(5.3)$ \\
Mass size (cm) & $8.4 \pm 5.3(3.0-26.0)$ \\
Bulky mass (> 10 cm) & $4(21.1)$ \\
Harvested no. of lymph nodes & $23.2 \pm 21.1(0.0-62.0)$ \\
No. of positive lymph node & $2.2 \pm 3.8(0.0-11.0)$ \\
\hline Values are presented as number (\%) or mean \pm standard deviation (range).
\end{tabular}


$(\mathrm{n}=0,0.0 \%)$, and IVE $(\mathrm{n}=2,10.5 \%)$. The Lugano staging results were: $\mathrm{I}(\mathrm{n}=2,10.5 \%)$, III $(\mathrm{n}=5,26.4 \%)$, II2 ( $\mathrm{n}=0,0.0 \%)$, IIE $(\mathrm{n}=10$, $52.6 \%)$, and IV $(n=2,10.5 \%)$. The depths of the tumor invasion were: mucosa/submucosa $(n=0,0.0 \%)$, muscularis propria $(n=3$, $15.8 \%)$, subserosa $(n=4,21.1 \%)$, serosa/adjacent organ involve-

Table 5. Pathologic finding after surgery of gastrointestinal diffuse large B cell lymphoma

\begin{tabular}{|c|c|}
\hline Pathologic results & Patients $(n=19)$ \\
\hline \multicolumn{2}{|l|}{ Paris classification } \\
\hline \multicolumn{2}{|l|}{ T stage } \\
\hline 1 & 0 \\
\hline 2 & $3(15.8)$ \\
\hline 3 & $14(73.7)$ \\
\hline 4 & $2(10.5)$ \\
\hline \multicolumn{2}{|l|}{ N stage } \\
\hline 0 & $10(52.6)$ \\
\hline 1 & $4(21.1)$ \\
\hline 2 & $5(26.3)$ \\
\hline 3 & 0 \\
\hline \multicolumn{2}{|l|}{ M stage } \\
\hline 0 & $19(100.0)$ \\
\hline \multicolumn{2}{|l|}{ Bone marrow biopsy } \\
\hline 1 & 0 \\
\hline 2 & 0 \\
\hline Bx & $17(89.5)$ \\
\hline BO & $2(10.5)$ \\
\hline B1 & 0 \\
\hline \multicolumn{2}{|l|}{ Depth of invasion, no. (\%) } \\
\hline Mucosa/submucosa & 0 \\
\hline Muscularis propria & $3(15.8)$ \\
\hline Subserosa & $4(21.1)$ \\
\hline Serosa/adjacent organ involvement, or perforation & $10(52.6)$ \\
\hline \multicolumn{2}{|l|}{ Ann Arbor stage } \\
\hline IE & $9(47.4)$ \\
\hline$\| \mathrm{E}$ & $8(42.1)$ \\
\hline IIIE & 0 \\
\hline IVE & $2(10.5)$ \\
\hline \multicolumn{2}{|l|}{ Lugano stage } \\
\hline 1 & $2(10.5)$ \\
\hline$\| 1$ & $5(26.4)$ \\
\hline$\| 2$ & 0 \\
\hline IIE & $10(52.6)$ \\
\hline IV & $2(10.5)$ \\
\hline \multicolumn{2}{|l|}{ IPI score } \\
\hline Low (0 or 1) & $11(57.9)$ \\
\hline Low-intermittent (2) & 7 (36.8) \\
\hline High-intermittent (3) & $1(5.3)$ \\
\hline High (4 or 5 ) & 0 \\
\hline
\end{tabular}

$\mathrm{IPI}$, international prognostic index. ment, or perforation $(\mathrm{n}=10,52.6 \%)$. The IPI scores were: low ( $\mathrm{n}=11,57.9 \%)$, low-intermittent $(\mathrm{n}=7,36.8 \%)$, high-intermittent $(\mathrm{n}=1,5.3 \%)$, and high $(\mathrm{n}=0,0.0 \%)$ (Table 5$)$.

\section{Immunochemistry results for gastrointestinal DLBL}

In the present study, B-lymphocyte antigen (CD20) was positive $(\mathrm{n}=17,89.5 \%)$ in most of the patients. B-cell lymphoma 2 (BCL-2) was positive in 5 patients (26.3\%). B-cell lymphoma 6 (BCL-6) was positive in 4 patients (21.1\%). CD3 was positive in only 1 patient (5.3\%). CD10 was positive in 4 patients (21.1\%). CD79a was positive in 5 patients (26.4\%). Multiple myeloma oncogene-1 (MUM1) was positive in 4 patients (21.1\%). A high level of Ki-67 (>70\%) was found in 12 patients (63.2\%) (Table 6).

\section{Oncologic outcomes of surgical management for gastrointestinal DLBL}

The response to adjuvant chemotherapy after surgery was good in most of the patients. Complete remission occurred in 16 patients (84.2\%), partial remission with stable disease occurred in 1 patient (Ann Arbor Stage IVa) (5.3\%). Two patients (10.5\%) died. One patient (Ann Arbor Stage IVa) had neutropenic sepsis during adjuvant chemotherapy, and one other patient (Ann Arbor Stage IE) had disseminated intravascular coagulation after surgery. There

Table 6. The result of immunochemistry for gastrointestinal diffuse large B cell lymphoma

\begin{tabular}{|c|c|c|c|c|c|c|c|c|}
\hline & BCL-2 & BCL-6 & $\mathrm{CD} 3$ & CD10 & $\mathrm{CD} 20$ & CD79a & MUM-1 & Ki-67 (\%) \\
\hline 1 & ND & + & - & - & + & ND & + & $50-60$ \\
\hline 2 & + & ND & - & - & + & ND & ND & 80 \\
\hline 3 & ND & - & - & - & + & ND & + & $80-90$ \\
\hline 4 & ND & ND & - & ND & + & + & ND & 30 \\
\hline 5 & ND & ND & - & ND & + & ND & ND & High \\
\hline 6 & ND & - & - & - & + & ND & - & 90 \\
\hline 7 & + & + & - & + & + & ND & ND & 90 \\
\hline 8 & ND & + & - & + & + & ND & + & $60-70$ \\
\hline 9 & + & - & ND & - & + & ND & ND & 90 \\
\hline 10 & + & ND & - & - & + & ND & ND & 80 \\
\hline 11 & - & + & ND & ND & ND & + & ND & High \\
\hline 12 & ND & ND & - & - & + & ND & + & $70-80$ \\
\hline 13 & + & ND & - & + & + & + & ND & 90 \\
\hline 14 & ND & ND & - & ND & + & ND & ND & 10 \\
\hline 15 & - & - & ND & ND & + & + & ND & 80 \\
\hline 16 & ND & ND & - & + & + & ND & ND & 80 \\
\hline 17 & ND & ND & + & ND & - & ND & ND & Low \\
\hline 18 & ND & ND & - & ND & + & ND & ND & 60 \\
\hline 19 & ND & ND & ND & ND & + & + & ND & ND \\
\hline
\end{tabular}

$\mathrm{BCL}$, B-cell lymphoma; CD, cluster of differentiation; MUM-1, multiple myeloma oncogene-1; ND, not done. 

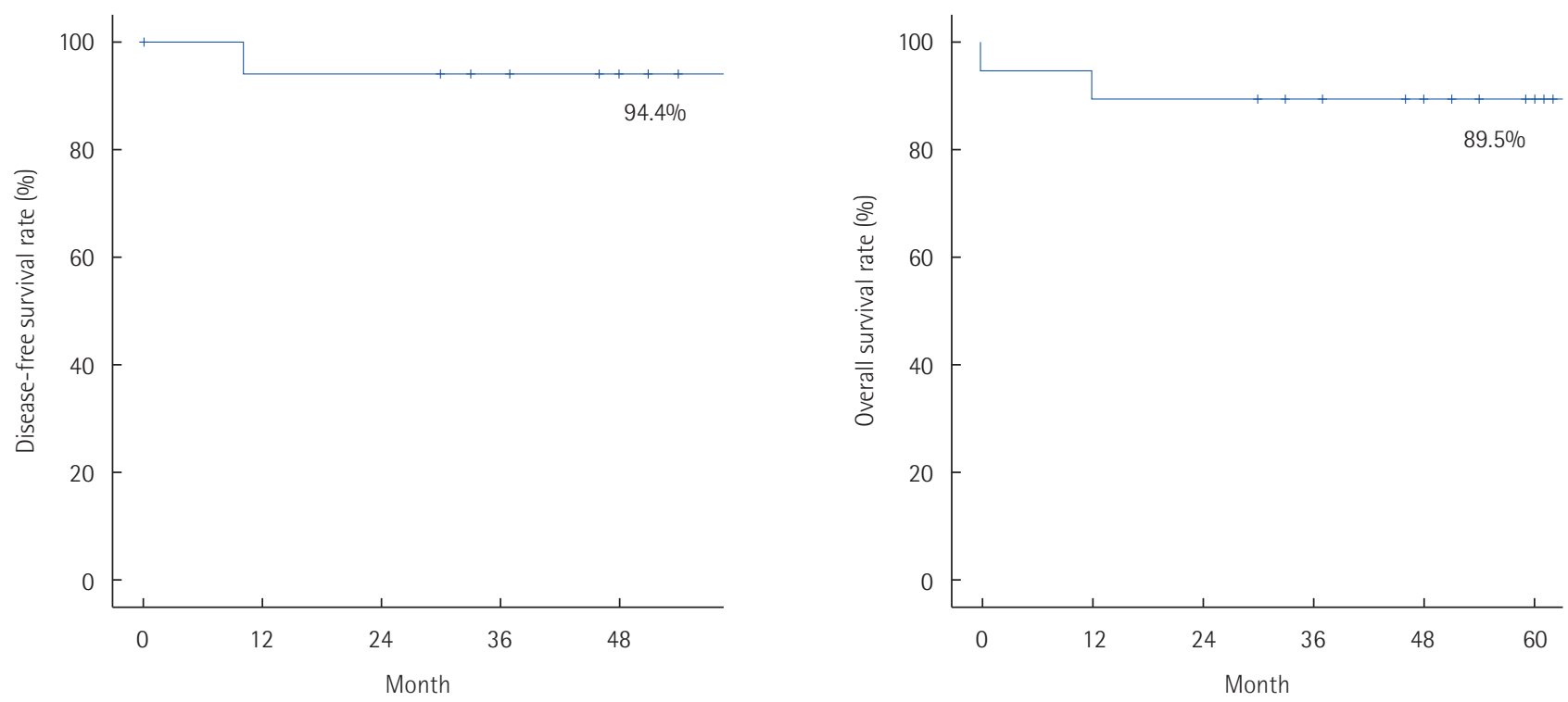

Fig. 2. Oncologic outcomes of surgical management for gastrointestinal diffuse large B cell lymphoma.

was no disease progression in the present study. With a median follow up of 49.2 months, the 5-year DFS rate was $94.4 \%$ and the 5 -year OS rate was $89.5 \%$ (Fig. 2).

\section{DISCUSSION}

Extranodal DLBL occurs in the gastrointestinal tract, and DLBL is the most common subtype in the small intestine and large intestine and the second most common subtype in the stomach and duodenum, after mucosa-associated lymphoid tissue lymphoma and follicular lymphoma, respectively [14]. In the present study, small intestine and large intestine DLBL $(\mathrm{n}=15,78.9 \%)$ were the most common subtypes. The second most common subtype was stomach DLBL $(n=4,21.1 \%)$. In the small and large intestine, the sites that were most involved were the terminal ileum $(\mathrm{n}=4$, $21.1 \%)$, the terminal ileum and the cecum $(\mathrm{n}=7,36.8 \%)$, the cecum $(n=3,15.8 \%)$, and the appendix $(n=1,5.3 \%)$. In the present study, no other sites were involved.

The most common symptoms of gastrointestinal DLBL are abdominal pain, nausea, and abdominal discomfort; B symptoms are very rare [15]. Hematochezia or hematemesis account for $20 \%-$ $30 \%$ of advanced stage DLBL [16]. In the present study, the most common symptoms were abdominal pain $(\mathrm{n}=15,78.9 \%)$ and hematochezia, which occurred in 2 patients (10.5\%). Moreover, none of the patients had B symptoms. Intussusception is usually associated with benign lesions, and in $14 \%$ of all cases it is associated with malignant lesions [17]. Primary lymphomas in the small intestine account for less than $2 \%$ of all gastrointestinal malignancies and $10 \%-20 \%$ of small intestine malignancies [18]. In the present study, 5 patients (26.3\%) had intussusceptions, all of which occurred in the ileocecal area. Perforation is an unusual symptom of gastrointestinal DLBL; however, the occurrence of perforations is potentially life threatening and related to morbidity from sepsis, multiple organ failure, prolonged hospital stay, and postoperative complications, including wound infection and delayed adjuvant therapy. Vaidya et al. [19] reported that, among patients with primary gastrointestinal lymphoma, 49 of 1,062 patients (4.61\%) had perforation as an initial symptom. In the present study, 2 of the 19 patients (10.5\%) had bowel perforation as an initial presenting symptom, and the perforation sites were the terminal ileum and the cecum.

Primary gastrointestinal DLBL generally expresses pan B-cell markers, such as CD19, CD20, CD22, CD79a, occasionally MUM- $1+$, and bcl-2+, and 50\%-75\% of cases express surface or cytoplasmic immunoglobulins [20,21]. In a study of 49 primary gastrointestinal DLBL cases, the histology and immunophenotyping showed that CD20+ and CD3- were the markers in all the cases [22]. On average, the Ki-67 labeling index was 68.3\% (range, $35 \%-90 \%$ ) and CD10 was positive in $44.9 \%$ of the cases, CD5 was positive in $4.1 \%$ of the cases, and c-MYC was positive in $23.4 \%$ of the cases [22]. In the present study, CD20 was positive in most of the cases $(89.5 \%)$ and BCL-2 was positive in $26.3 \%$ of the cases, BCL- 6 was positive in $21.1 \%$ of the cases, CD 10 was positive in $21.1 \%$ of the cases, CD 79a was positive in $26.4 \%$ of the cases, and MUM-1 was positive in $21.1 \%$ of the cases. A high level of Ki-67 (>70\%) was found in 12 patients (63.2\%).

In the present study, 18 of the 19 patients underwent surgery with radical resection; one patient underwent an appendectomy. 
Emergency surgery was performed for $36.8 \%(\mathrm{n}=7)$ of the patients in the present study. One published study from Turkey reported that the 5 -year survival rate was $64.3 \%$ in 17 primary small intestinal non-Hodgkin's lymphoma patients (12 patients DLBL) after emergency surgery [23]. In the present study, the prognosis of all cases with emergency surgery was good. The treatment of primary intestinal DLBL is a controversial issue. Because primary intestinal DLBL is a very rare disease, and there are few large scale prospective randomized studies, there is no consensus on the optimal treatment. Various treatment models, such as systemic chemotherapy, have been used to treat nodal DLBL; primary surgical resection of gastrointestinal lesions and postoperative chemotherapy has also been used. One multicenter study (Korean Lymphoma Group) reported on the oncologic outcomes of 345 patients diagnosed with primary intestinal DLBL [24]. That study reported that patients with localized disease (Lugano stage I/II) that underwent surgery plus chemotherapy had a lower relapse rate (15.3\%) than patients that only received chemotherapy $(36.8 \%, \mathrm{P}<0.001)$ [24]. The 3-year OS rate was $91.0 \%$ in the surgery plus chemotherapy group and $62.0 \%$ in the group that only received chemotherapy $(\mathrm{P}<0.001)$ [24]. In another prospective non-randomized study of 40 patients, all patients received primary resection with lymph node dissection and postoperative $\mathrm{CHOP}$ chemotherapy; the 5 -year OS rate was $88.9 \%$ and the 5 -year DFS rate was $83.1 \%$ [25]. In a retrospective study of 56 patients with surgery plus chemotherapy, a 5-year OS rate of $86.4 \%$ was reported [26].

There are several prognosis factors for primary gastrointestinal DLBL. Surgical resection plus chemotherapy is an independent prognostic factor for OS. In a retrospective study of 224 patients, the bulk of the tumor $(>5 \mathrm{~cm})$ proved to be a significant prognostic factor for DLBL treatment outcome [27]. The OS rate was affected by the tumor bulk, which was $91.23 \%$ vs. $86.8 \%$ if the tumor bulk was less than versus more than or equal to the median, respectively $(P=0.05)$ [27]. In another retrospective multicenter study of 345 patients, multivariate analysis demonstrated that surgical resection plus chemotherapy was an independent prognostic factor for OS [24]. In that study, because most of the patients with Lugano stage I/II and low IPI risk underwent surgery, the prognostic value was diluted in the multivariate analysis [24]. In another retrospective multicenter study of 114 patients, multivariate analysis identified treatment response, elevated serum lactic acid dehydrogenase (LDH) levels, and ECOG performance status as independent predictors of survival [28]. In a retrospective study of 85 patients, the IPI score was found to be an independent prognosis risk factor of OS (risk ratio $=3.609,95 \%$ confidence interval, 2.2034-6.404; $\mathrm{P}<0.01$ ) [29]. In the present study, most patients had a low IPI score and Lugano stage I/II, and their prognosis was good with median follow up of 49.2 months. In conclusion, surgery for primary gastrointestinal DLBL is feasible and acceptable. Low staging of primary gastrointestinal DLBL has good prognosis.

\section{CONFLICT OF INTEREST}

No potential conflict of interest relevant to this article was reported.

\section{ACKNOWLEDGMENTS}

This work was supported by the Soonchunhyang University Research Fund.

\section{REFERENCES}

1. Zucca E, Roggero E, Bertoni F, Cavalli F. Primary extranodal non-Hodgkin's lymphomas. Part 1: gastrointestinal, cutaneous and genitourinary lymphomas. Ann Oncol 1997;8:727-37.

2. Swerdlow SH; World Health Organization; International Agency for Research on Cancer. WHO classification of tumours of haematopoietic and lymphoid tissues. 4th ed. Lyon: International Agency for Research on Cancer; 2017.

3. Freeman C, Berg JW, Cutler SJ. Occurrence and prognosis of extranodal lymphomas. Cancer 1972;29:252-60.

4. Sabattini E, Bacci F, Sagramoso C, Pileri SA. WHO classification of tumours of haematopoietic and lymphoid tissues in 2008: an overview. Pathologica 2010;102:83-7.

5. Koch P, del Valle F, Berdel WE, Willich NA, Reers B, Hiddemann W, et al. Primary gastrointestinal non-Hodgkin's lymphoma: I. Anatomic and histologic distribution, clinical features, and survival data of 371 patients registered in the German Multicenter Study GIT NHL 01/92. J Clin Oncol 2001;19:3861-73.

6. Papaxoinis G, Papageorgiou S, Rontogianni D, Kaloutsi V, Fountzilas G, Pavlidis N, et al. Primary gastrointestinal non-Hodgkin's lymphoma: a clinicopathologic study of 128 cases in Greece. A Hellenic Cooperative Oncology Group study (HeCOG). Leuk Lymphoma 2006;47:2140-6.

7. Lewin KJ, Ranchod M, Dorfman RF. Lymphomas of the gastrointestinal tract: a study of 117 cases presenting with gastrointestinal disease. Cancer 1978;42:693-707.

8. Oken MM, Creech RH, Tormey DC, Horton J, Davis TE, McFadden ET, et al. Toxicity and response criteria of the Eastern Cooperative Oncology Group. Am J Clin Oncol 1982;5:649-55.

9. International Non-Hodgkin's Lymphoma Prognostic Factors Project. A predictive model for aggressive non-Hodgkin's lymphoma. N Engl J Med 1993;329:987-94.

10. Greene FL. Cancer staging handbook: TNM classification of ma- 
lignant tumors. New York: Springer; 2002.

11. Ruskone-Fourmestraux A, Dragosics B, Morgner A, Wotherspoon A, de Jong D. Paris staging system for primary gastrointestinal lymphomas. Gut 2003;52:912.

12. Musshoff K. Clinical staging classification of non-Hodgkin's lymphomas (author's transl). Strahlentherapie 1977;153:218-21.

13. Rohatiner A, d'Amore F, Coiffier B, Crowther D, Gospodarowicz $\mathrm{M}$, Isaacson P, et al. Report on a workshop convened to discuss the pathological and staging classifications of gastrointestinal tract lymphoma. Ann Oncol 1994;5:397-400.

14. Nakamura S, Matsumoto T, Iida M, Yao T, Tsuneyoshi M. Primary gastrointestinal lymphoma in Japan: a clinicopathologic analysis of 455 patients with special reference to its time trends. Cancer 2003; 97:2462-73.

15. Kim SG. Gastrointestinal lymphoma. Korean J Gastrointest Endosc 2010;41:1-4.

16. Aledavood A, Nasiri MR, Memar B, Shahidsales S, Raziee HR, Ghafarzadegan K, et al. Primary gastrointestinal lymphoma. J Res Med Sci 2012;17:487-90.

17. Begos DG, Sandor A, Modlin IM. The diagnosis and management of adult intussusception. Am J Surg 1997;173:88-94.

18. Azar T, Berger DL. Adult intussusception. Ann Surg 1997;226:1348.

19. Vaidya R, Habermann TM, Donohue JH, Ristow KM, Maurer MJ, Macon WR, et al. Bowel perforation in intestinal lymphoma: incidence and clinical features. Ann Oncol 2013;24:2439-43.

20. Harris NL, Jaffe ES, Diebold J, Flandrin G, Muller-Hermelink HK, Vardiman J. Lymphoma classification: from controversy to consensus: the R.E.A.L. and WHO Classification of lymphoid neoplasms. Ann Oncol 2000;11 Suppl 1:3-10.

21. Daum S, Ullrich R, Heise W, Dederke B, Foss HD, Stein H, et al. Intestinal non-Hodgkin's lymphoma: a multicenter prospective clin- ical study from the German Study Group on Intestinal non-Hodgkin's Lymphoma. J Clin Oncol 2003;21:2740-6.

22. Nagakita K, Takata K, Taniguchi K, Miyata-Takata T, Sato Y, Tari A, et al. Clinicopathological features of 49 primary gastrointestinal diffuse large B-cell lymphoma cases; comparison with location, cell-of-origin, and frequency of MYD88 L265P. Pathol Int 2016;66: 444-52.

23. Avci T, Yabanoglu H, Arer IM, Kocer NE, Caliskan K, Borcek P, et al. Primary small intestinal non-Hodgkin lymphoma diagnosed after emergency surgery. Ulus Travma Acil Cerrahi Derg 2017;23: 128-33,

24. Kim SJ, Kang HJ, Kim JS, Oh SY, Choi CW, Lee SI, et al. Comparison of treatment strategies for patients with intestinal diffuse large B-cell lymphoma: surgical resection followed by chemotherapy versus chemotherapy alone. Blood 2011;117:1958-65.

25. Lee J, Kim WS, Kim K, Ahn JS, Jung CW, Lim HY, et al. Prospective clinical study of surgical resection followed by $\mathrm{CHOP}$ in localized intestinal diffuse large B cell lymphoma. Leuk Res 2007;31:359-64.

26. Hwang HS, Yoon DH, Suh C, Park CS, Huh J. Intestinal diffuse large B-cell lymphoma: an evaluation of different staging systems. J Korean Med Sci 2014;29:53-60.

27. Abdelhamid T, Samra M, Ramadan H, Mehessin M, Mokhtar N. Clinical prognostic factors of diffuse large B cell non-Hodgkin lymphoma: a retrospective study. J Egypt Natl Canc Inst 2011;23: 17-24.

28. Li X, Shen W, Cao J, Wang J, Chen F, Wang C, et al. Treatment of gastrointestinal diffuse large B cell lymphoma in China: a 10-year retrospective study of 114 cases. Ann Hematol 2012;91:1721-9.

29. Song L, Cen X, Ou J, Wang W, Qiu Z, Song Y, et al. Long term follow-up and prognostic analysis of 85 cases with primary gastrointestinal diffuse large B cell lymphoma. Zhonghua Xue Ye Xue Za Zhi 2014;35:909-13. 